\title{
DEMOCRACIA E LUTA POR HEGEMONIA ${ }^{1}$
}

\author{
Monica Loyola Stival ${ }^{2}$
}

\begin{abstract}
Resumo: Este artigo parte do conceito de democracia como forma indeterminada de poder, em um esforço para pensar o sentido concreto da organização social orientada pela democracia, assim compreendida. A democracia parece admitir tanto uma organização material socialista quanto liberal. Daí a necessidade de distinguir o nível formal de abertura democrática e o nível material de luta por hegemonia em que essa alternativa aparece, entendendo ambos como determinações contingentes em disputa.

Palavras-chave: democracia, liberalismo, socialismo, inimigo, hegemonia.
\end{abstract}

Tendo como base o conceito de democracia como indeterminação (Lefort), este artigo procura pensar a distinção entre dois níveis de valor; um relativo à forma histórica (democrática ou totalitária) e outro relativo à ordem social (socialista ou liberal). Sem as amarras da filosofia da história, as duas dimensões mostram-se valor em disputa, de modo que a própria forma do poder - além da luta por hegemonia na dimensão material - é horizonte político. Assim, um primeiro passo deste artigo é apresentar a noção de democracia como indeterminação. Em seguida, após situar o sentido conceitual que "inimigo" pode ter nesse quadro teórico, trata-se de esclarecer a diferença entre duas maneiras concretas de organização social. Essa diferença não se apresenta, seguramente, como mera alternativa teórica, de modo que o esforço, na sequência do artigo, é problematizar o sentido teórico da materialidade liberal, abrindo espaço para uma conclusão que aponte o interesse de outro modelo material. Portanto, uma vez estabelecida a dimensão da organização social em que narrativas específicas adquirem hegemonia, é possível sugerir o interesse em construir um ethos solidário, restituindo um sentido amplo ao socialismo, em oposição ao ethos liberal de nossa época.

\section{I - A indeterminação como democracia}

A democracia não é o fim da disputa política, mas sua condição de possibilidade. A democracia é pensada por alguns autores do final do século XX e início do XXI como indeterminação em um conflito político, o que tornaria específica a dominação. Para Rancière, por exemplo, a política nasce quando a dominação encontra nos dominados uma entidade específica, uma resistência na forma de alguma organização ou identidade social.

\footnotetext{
${ }^{1}$ Este artigo deve ser lido como um esboço, um exercício de reflexão levado a cabo a partir de diversas leituras que compuseram o projeto coletivo de pesquisa "A política na filosofia do século XX".

2 Professora do departamento de filosofia da UFSCar.
} 
Podemos nos valer aqui, de partida, dessa definição apresentada por Rancière quando discute o começo da política entre os gregos: "Há política quando existe uma parcela dos sem-parcela, uma parte ou um partido dos pobres. Não há política simplesmente porque os pobres se opõem aos ricos. Melhor dizendo, é a política - ou seja, a interrupção dos simples efeitos de dominação dos ricos - que faz os pobres existirem enquanto entidade" . Significa que a oposição que constitui "o político" não precisa ser determinada como oposição entre identidades de tipo estatal, como sugere Schmitt na oposição amigo / inimigo. O central do político pode ser entendido como a instituição da comunidade como divisão, de modo mais amplo - neste ponto - que o conceito do político schmittiano, por envolver formas diversas de determinação da distinção prática e conceitual amigo / inimigo.

Porém, antes de qualificar as oposições próprias do político em sua forma democrática, nesse sentido amplo, vejamos o que significa a indeterminação. Assim como Foucault, Lefort procura destacar as formas da história como momentos de uma abertura que, contudo, sedimentam certa unidade de longos períodos, destacados como formas, epistemes ou épocas da história. Lefort define a democracia como "a sociedade histórica por excelência, sociedade que, por sua forma, acolhe e preserva a indeterminação, em contraste notável com o totalitarismo que, edificando-se sob o signo da criação do novo homem, na realidade agencia-se contra essa indeterminação, pretende deter a lei de sua organização e de seu desenvolvimento, e se delineia secretamente no mundo moderno enquanto sociedade sem história"4.

A forma da democracia é propriamente histórica, é indeterminada. Porém, para Lefort, a indeterminação é própria de uma forma da história. Nesse sentido, ele pensa essa indeterminação como um espaço simbólico cuja natureza é preciso redefinir. Isso porque é preciso marcar o limite teórico que a distinção de formas específicas da história traz à tona, problema que Lefort compartilha com Foucault quando este contamina seu "nominalismo em história" com a distinção crítica de epistemes ou épocas específicas. Por isso o contraponto de Foucault às filosofias da história não é suficiente para fornecer sentido político radical e coletivo às práticas e narrativas historicamente constituídas. Ao contrário, o espaço simbólico em que se definem oposições fundamentais do político, como político, não sendo essa unidade quase-transcendental que encontramos em Lefort ou Foucault, pode ser pensado como resultado do excedente de sentido que articula diferentes lutas sociais, diferentes posições concretas do sujeito. As unidades políticas e a forma do político, aqui, não ultrapassam os espaços em que se formulam e se articulam concretamente.

\footnotetext{
${ }^{3}$ RANCIÈRE, O desentendimento, p. 26.

${ }^{4}$ LEFORT, C. "A questão da democracia”, p. 31.
} 
Assim, é possível recusar o caráter a-histórico do simbólico em Lefort e da crítica arqueológica de Foucault. Uma das formulações recentes a esse respeito, que vai na direção de uma radicalização do sentido histórico da forma social, pode ser encontrada no livro de Laclau e Mouffe intitulado Hegemonia e estratégia socialista. Nele encontra-se um caminho para outra formulação teórica e prática a respeito do simbólico - formulação que os autores trazem de Rosa Luxemburgo - e para o sentido da indeterminação.

"É nos reflexos múltiplos, serpenteantes, do espelho partido da 'necessidade histórica', que uma nova lógica do social começa a se insinuar, a qual só conseguirá ser pensada pelo questionamento da própria literalidade dos termos que ela articula" ${ }^{\text {. O }}$ central nessa nova lógica do social é o excesso de sentido em relação à literalidade de lutas e demandas específicas. Discutindo o simbólico como "transbordamento do significante pelo significado", Laclau e Mouffe encontram em Rosa Luxemburgo uma formulação da unidade como dimensão do símbolo, que é uma unidade indeterminada porque é o transbordamento das determinações particulares, ou seja, das "posições de sujeito" ou "pontos de antagonismo" (portanto, não é necessário manter o sentido de classe desta unidade, que é o modo como ela se determina para Rosa Luxemburgo).

"Ora, por um lado, a análise de Rosa Luxemburgo multiplicou os pontos de antagonismo e as formas de luta - que, daqui em diante, chamaremos de posições de sujeito -, ao ponto de explodir toda capacidade de controle ou planejamento dessas lutas por parte de uma liderança sindical ou política; por outro lado, ela propôs a sobredeterminação simbólica como mecanismo concreto de unificação das mesmas lutas" ${ }^{\prime 6}$. Feita a crítica da conclusão pela unificação como classe, resta o interessante conceito de simbólico como excesso de sentido que forja certa unidade - que pode ser entendida como unidade narrativa. A sobredeterminação simbólica escapa à imposição por liderança, mas nem por isso se furta à construção e disputa pelo sentido de cada luta específica e, com isso, da narrativa que a excede e a vincula a outras lutas específicas, lutas locais.

Portanto, o que se ganha em retomar o sentido do termo "simbólico" na discussão de Rosa Luxemburgo, pelo menos na leitura proposta por Laclau e Mouffe, é que a forma é produto do excesso de sentido das diferentes lutas concretas. O simbólico não está fora da história, de modo que a forma da história é ela própria a expressão do excesso de sentido empírico. A partir deste sentido do simbólico pode-se renovar o significado dos conceitos e distinguir a dimensão da forma democrática e a dimensão da luta por hegemonia.

Como nota Lefort, o essencial "é que a democracia institui-se e se mantém pela dissolução dos marcos de referência da certeza. A democracia inaugura uma história na qual os homens estão à prova de uma indeterminação última quanto ao fundamento do Poder, da

${ }^{5}$ LACLAU / MOUFFE, Hegemonia e estratégia socialista, p. 58.
${ }^{6}$ LACLAU / MOUFFE, Hegemonia e estratégia socialista, p. 62. 
Lei e do Saber, e quanto ao fundamento da relação de um com o outro, sob todos os registros da vida social"”. Porém, essa desagregação pode se resolver em uma posição individual em diferentes relações e diferentes registros da vida social, como requer o liberalismo, ou pode se resolver em posições do sujeito que se dão conforme referências de certeza parciais e circunstanciais - como sobredeterminação - que articulam um e outro nesse ou naquele registro da vida social, ainda que como um momento da história do registro social em jogo.

Em um caso ou em outro, na organização concreta de tipo liberal ou socialista ambos na forma democrática, e justamente por isso -, as relações aparecem como oposições, agonismos e antagonismos. Ora, a própria indeterminação da democracia implica que essas oposições tenham eventualmente o sentido de conflito, pois há modos de existência que ameaçam outros modos de existência.

A aposta de Mouffe no agonismo - relação com adversários - como solução para o antagonismo - relação amigo e inimigo - é frágil e ideal, pois pressupõe um campo comum que apaga a dominação. É preciso descrever as lutas concretas em termos de agonismo e antagonismo, como modos distintos e reais de conflito. Caso contrário, cairíamos na mesma pacificação pressuposta por uma teoria do discurso em que as disputas se estabelecem tendo como fundamento a aposta na possibilidade do entendimento, isto é, tendo como fundamento o solo comum da linguagem, e não o solo centrífugo dos diferentes modos de existência.

É o caso do latifúndio frente à agricultura familiar, o caso do racismo frente aos negros, das fronteiras estatais frente aos refugiados, do "ocidente" frente aos indígenas, etc. $\mathrm{Ou}$, com o sucesso de uma luta por hegemonia socialista, que primasse pelas formas coletivas e solidárias de vida, seria o caso da agricultura familiar frente ao latifúndio, o caso dos negros frente ao racismo, dos refugiados frente às fronteiras excludentes, dos indígenas frente ao colonialismo cultural, etc. De um modo ou de outro - é o modo que está em disputa, enquanto se pode disputar - a forma democrática é um terreno que se define pela imanência do inimigo.

\section{II - A imanência do inimigo}

Em Metafísicas Canibais, Viveiros de Castro adverte que a questão da "imanência do inimigo" apreendida na etnografia ameríndia não é de modo algum "um a priori identitário do conceito de 'político' ao modo de Carl Schmitt" ${ }^{\text {. }}$ De fato, o inimigo em Schmitt é a determinação negativa que estabelece, por oposição dialética, a identidade do "amigo".

\footnotetext{
${ }^{7}$ LEFORT, “A questão da democracia”, p. 34.

${ }^{8}$ VIVEIROS DE CASTRO, Metafísicas Canibais, p. 226.
} 
Contudo, o conceito de amigo de Schmitt tem a vantagem de retirar a alteridade amigo-inimigo da tranquila identidade da fórmula clássica segundo a qual "o Amigo é outrem, mas outrem como 'momento' do Eu"9. Se a dissolução dessa totalidade pacificadora introduz a diferença como modo necessário das relações políticas e sociais, ela permanece presa em Schmitt a uma forma corporificada de poder, a uma forma não democrática de história. A figura do "sujeito da soberania" é o signo dessa corporeidade e, com ela, signo da identidade na forma de uma unidade política. Essa identidade é circunscrita teologicamente pelo jus bellis, que é o direito de guerra contra todo outro modo de existência que ameaça aniquilar seu próprio modo de existência.

O direito de guerra frente a modos de existência antagônicos - nem todas as oposições podem se resolver em agonismos, como adversários, por mais perigosa que possa ser essa constatação ${ }^{10}$ - é em Schmitt identificado com uma esfera estatal, de modo que a unidade política se fecha em um tipo de soberania jurídica. Para renovar o sentido da oposição em jogo é preciso abandonar o pressuposto schmittiano de que a decisão é "um elemento especificamente jurídico"11. Toda teoria do estado de exceção depende desta premissa, amarrando a não-norma ao sentido jurídico da ausência de norma ou das medidas de exceção. Com isso, trata-se da legitimidade das medidas de exceção, localizando o sujeito da soberania, mas não do sentido político das medidas de exceção. O sentido político da suspensão, o caso concreto que dá sentido e valor à ação do soberano, a posição política que confere legitimidade é anterior à legitimidade do soberano que suspende o direito positivo em um momento de crise (este momento para o qual o liberalismo, mostra Schmitt, não tem resposta). No liberalismo, quando o soberano é estabelecido pela primazia do jurídico - seguindo a premissa de que a decisão seria elemento especificamente jurídico - confunde-se a prerrogativa política com a prerrogativa do sistema jurídico, como se este estivesse "limpo" de política ou a determinasse. O sentido político das oposições requer que se pense a unidade política sem se ater prioritariamente ao registro jurídico e estatal (de um direito de guerra), mas considerando antes o plano das alianças e organizações políticas concretas, dos vínculos morais e políticos de diferentes grupos no interior dos Estados ou, melhor dizendo, independentemente da unidade estatal.

Isso significa que as posições concretas implicam modos de existência distintos e opostos, os quais, muitas vezes, são antagônicos e exclusivos. Significa, portanto, que o "inimigo", além de não ser um "a priori identitário", uma vez que essas alianças e organizações concretas são fluidas e historicamente delimitadas, também não se reduz a

\footnotetext{
${ }^{9}$ VIVEIROS DE CASTRO, Metafísicas Canibais, p. 225.

${ }^{10}$ Não se pode dizer que há espaço para transformar todos os antagonismos em agonismo (inimigos como adversários, conflitos letais como semiconsensos discursivos) se olharmos para os genocídios nas periferias brasileiras, para a morte invisível de tantos refugiados deste início de século, para a aniquilação de indígenas por grileiros do agronegócio.

${ }^{11}$ SCHMITT, Teología política, p. 18.
} 
uma condição interestatal. O inimismo em sentido ameríndio parece corrigir duas premissas do modelo de Schmitt: que a distinção seja fixa e identitária, por um lado, e que ela seja prioritariamente estatal e jurídica, por outro.

Portanto, o que o "inimismo"12 da etnologia nos permite pensar - como instrumento conceitual que coloca questões para a compreensão do nosso modo de existência - é que a "imanência do inimigo" é também o sentido da forma democrática. Talvez possamos atualizar o sentido da cosmopráxis ameríndia para descobrir que a democracia, como forma em uma história aberta, como indeterminação, não é de maneira alguma o topos de uma igualdade, mas o topos de uma diferenciação constante, equivalente ao "inimismo" de que fala Viveiros de Castro. Trata-se de "trazer para dentro" da forma democrática o conceito amigo-inimigo, corrigindo a estagnação desses termos em identidades opostas que circunscreveriam unidades políticas relativamente autônomas e estatizadas. Essa correção pode ser feita a partir do sentido ameríndio de "inimigo".

Nesse sentido, a especulação aqui proposta é uma reformulação do par conceitual "amigo / inimigo", não na direção exclusiva do "adversário" do agonismo de Mouffe, mas na direção de uma instabilidade complexa entre um e outro, entre violência e debate, entre inimigo e adversário, entre antagonismo e agonismo. Isso permite trazer a alteridade para dentro da democracia, entendendo os conflitos como oposições que fundamentam concretamente a própria indeterminação da forma democrática ${ }^{13}$.

\section{III - Dois níveis de valor: a dimensão da disputa na forma democrática}

"Posso não concordar com o que você diz, mas defenderei até a morte seu direito de dizê-lo". Essa máxima, de autoria controversa, permite ilustrar certa hierarquia de valores. Uma coisa é a possibilidade da enunciação, outra coisa é o que é dito. De um lado, a indeterminação da forma democrática deixa aberta a enunciação; de outro lado, a disputa pelo conteúdo da enunciação. Esta última depende daquela forma indeterminada. Quer dizer, há disputa no nível da forma e, em segundo plano, disputa no nível material. Assim, a divisa acima explicita a hierarquia entre a forma da indeterminação - democrática, antitotalitária - e a materialidade do que é defendido como valor concreto.

Pode-se pensar então dois níveis hierarquizáveis de posição política:

1) Valor quanto à forma histórica: indeterminação; dimensão formal.

\footnotetext{
${ }^{12}$ VIVEIROS DE CASTRO, Metafísicas canibais, p. 227.

${ }^{13}$ Embora Chantal Mouffe traga ideia semelhante quando discute o problema da unidade política a partir de Schmitt, é preciso discutir a caracterização do espaço em que tais oposições tomam corpo como "democracia liberal": "De fato, não há articulação hegemônica sem a determinação de uma fronteira, a definição do 'eles'. Mas no caso da política liberal-democrática essa fronteira é uma fronteira interna, e o 'eles' não é um estranho permanente" (Mouffe, "Schmitt and the paradox of liberal democracy", p. 56). Voltaremos a esse assunto quando tratarmos do liberalismo.
} 
2) Valor quanto à ordem social: disputa por hegemonia; dimensão material.

Ambos são contingentes e dependem da atividade social e política. Não há nenhum tipo de necessidade - lógica, estrutural ou natural - nessas duas dimensões da vida comunitária. Os dois níveis estão em disputa, o que quer dizer, principalmente, que a forma da história, assim como a organização empírica da vida social, está em disputa.

Essa contingência da racionalidade vigente nos dois níveis de determinação dos modos de vida não pode ser estancado por uma decisão de ordem racional, como supõem os teóricos da "democracia deliberativa". Neste ponto, pode-se acompanhar a crítica de Mouffe para ver que as relações de poder estabelecem uma fronteira "entre o que é e o que não é legítimo" que é política, "e por essa razão ela deveria permanecer contestável”, ao contrário do que asseguram autores da democracia deliberativa como Rawls e Habermas. Conclui Mouffe: "negar a existência de um tal momento de fecho (closure), ou apresentar a fronteira como ditada pela racionalidade ou moralidade, é naturalizar o que deveria ser percebido como uma articulação hegemônica contingente e temporária do 'povo' (the people) por meio de um regime particular de inclusão-exclusão"14.

Vejamos como pensar esses níveis de valor.

1) A dimensão da história se define pela forma do político, e a forma indeterminada do político chama-se democracia.

Ficamos, assim, com a circunscrição de Lefort sobre a "democracia", embora devase considerar a reformulação do estatuto do simbólico acima mencionada. O que é central na noção lefortiana de democracia é sua delimitação por oposição ao totalitarismo. Laclau e Mouffe, entretanto, dão margem à ideia de que a democracia é a possibilidade do totalitarismo: "o circuito discursivo da revolução democrática abre caminho para lógicas políticas tão diversas quanto o populismo e o totalitarismo de direita, por um lado, e uma democracia radical, por outro"15. Assim, eles entendem que há "uma nova possibilidade que emerge no próprio campo da democracia: a lógica do totalitarismo" "16. Mas se ele emerge desse campo, é apenas como inimigo imanente, como oposto absoluto que anula a primeira.

A democracia pode ser pensada como forma histórica essencialmente contrária ao totalitarismo. Por ser inteiramente histórica e concreta, essa forma da história está permanentemente em disputa. Por isso ela é também valor, por isso ela é também sensível à conjuntura política. Aliás, é apenas nessa medida que a conjuntura política pode alcançar alterações - ou impedir alterações - no nível geral da forma. Não há a priori impermeável à prática política concreta ou independente desta. Para haver sentido prático na forma histórica é preciso pensá-la em sua determinação prática, ainda que essa determinação seja a

\footnotetext{
${ }^{14}$ MOUFFE, "Schmitt and the paradox of liberal democracy", p. 49.

${ }^{15}$ LACLAU / MOUFFE, Hegemonia e estratégia socialista, p. 254.

${ }^{16}$ LACLAU / MOUFFE, Hegemonia e estratégia socialista, p. 276.
} 
postulação de uma forma indeterminada do exercício de governo, uma forma aberta a distintas racionalidades. Democracia seria a forma indeterminada, o espaço aberto em que essas diferentes racionalidades podem coexistir ou, em muitos casos, entrar em conflito. É na indeterminação que unidades contingentes podem se formar, opondo amigos e inimigos, opondo grupos e significações, opondo modos de existência distintos e eventualmente exclusivos. Portanto, se o político é a dimensão na qual a oposição amigo-inimigo toma corpo, a democracia é propriamente a única forma do político.

2) Se "a hegemonia é um tipo de relação política" ", essa relação hegemônica pode ser liberal ou socialista.

O termo "hegemonia" é usado aqui no sentido de Laclau e Mouffe, embora com a diferença radical que o deslocamento de nível aqui proposto implica, particularmente para o que poderá ser, então, a relação entre hegemonia e democracia. Este deslocamento permite inclusive lançar luz à ideia de que as formações hegemônicas são próprias da modernidade. Laclau e Mouffe não explicam o que permite distinguir algo como "modernidade" ou "contemporaneidade", mesmo reportando a centralidade da formação hegemônica a essa circunstância histórica. Na modernidade há um espaço aberto, "daí porque a forma hegemônica de política só se torna dominante no início dos tempos modernos"18. Porém, não basta levantar um exemplo - a comunidade camponesa medieval - para mostrar que não havia formas hegemônicas de articulação em tais circunstâncias e apenas depois, diante do caráter aberto (não-suturado) do social. O que é essa abertura? Ora, essa abertura, mostrou Lefort, é a democracia.

Assim, quando Laclau e Mouffe dizem que uma das condições para haver formação hegemônica é "a contínua redefinição dos espaços políticos e sociais e os constantes processos de deslocamento dos limites que constroem a divisão social" e que eles "são próprios da sociedade contemporânea" ${ }^{19}$, só podem fundar essa distinção em algo como o advento da forma democrática. Ora, nesse sentido, a democracia é condição para a formação hegemônica. É claro que eles reconhecem esse vínculo do ponto de vista histórico, pois a tese que defendem é "que foi somente a partir do momento em que o discurso democrático se dispôs a articular as diferentes formas de resistência à subordinação que surgiram as condições que permitiram a luta contra diferentes tipos de desigualdades $" 20$. Acontece que eles confundem o advento histórico da forma democrática - essa indeterminação do poder - com a determinação de referentes empíricos. Quer dizer, eles reconhecem a democracia como registro discursivo, na medida em que afirmam que "o princípio democrático da liberdade e da igualdade teve primeiro que se impor como nova

${ }^{17}$ LACLAU / MOUFFE, Hegemonia e estratégia socialista, p. 222.

${ }^{18}$ LACLAU / MOUFFE, Hegemonia e estratégia socialista, p. 218.

${ }^{19}$ LACLAU / MOUFFE, Hegemonia e estratégia socialista, p. 225.

${ }^{20}$ LACLAU / MOUFFE, Hegemonia e estratégia socialista, p. 237. 
matriz do imaginário social" ${ }^{21}$ com as posições igualitárias ou libertárias, ligadas efetivamente ao liberalismo.

Ora, o que é próprio do liberalismo e o que é próprio da democracia se confundem quando não se estabelece a distinção entre o nível da forma histórica - o político - e o nível da organização material desta ou daquela sociedade - a política. Portanto, afirmar com Laclau e Mouffe que "a ruptura com o ancien régime, simbolizada pela Declaração dos Direitos do Homem, forneceria as condições discursivas que permitiram propor as diferentes desigualdades como ilegítimas e antinaturais, tornando-as assim equivalentes como formas de opressão" é dizer que a democracia forneceu as condições discursivas que permitiram o liberalismo, isto é, a ideia da igualdade de condições e liberdade de pensamento e ação. Porém, distinguir esses níveis permite ver que a democracia não inaugura a igualdade; ela inaugura a indeterminação do poder.

Mas, então, em que sentido positivo podemos mobilizar o termo "hegemonia"? "Uma situação de hegemonia seria aquela em que o gerenciamento da positividade do social e a articulação das diversas demandas democráticas tivessem atingido um máximo de integração" 22 . Esta é a definição que nos interessa, assim como grande parte da discussão que a sustenta, segundo a qual não há determinação prévia das identidades sociais e não há sujeito social privilegiado. Laclau e Mouffe oferecem em Hegemonia e estratégia socialista uma revisão informada e extremamente interessante da história do marxismo, apontando com propriedade uma crítica contundente a três obstáculos principais que esta tradição teórica manteve diante de si: o classismo, o estatismo e o economicismo ${ }^{23}$. De modo geral, o livro prepara uma defesa do que seria a "democracia radical" a partir de uma atualização do conceito de "hegemonia". Embora discordemos do horizonte político defendido pela primeira expressão, certos aspectos do conceito de hegemonia permitem circunscrever a dimensão em que há luta pelo imaginário social.

“Toda posição hegemônica se baseia, portanto, num equilíbrio instável: a construção parte da negatividade, mas só se consolida na proporção em que consegue constituir a positividade do social" ${ }^{24}$. O excesso que unifica sentido só pode ocorrer nesse nível material de valor - por isso pode haver projeto anticapitalista -, sempre submetido ao primeiro nível, único modo de prática social em que não há determinação como totalitarismo. Ora, sendo assim, o simbólico é propriamente constituído nesse segundo nível, como excesso de sentido que resulta em uma narrativa hegemônica. Significa que até mesmo a opressão econômica pode ser entendida a partir da dominação, a partir das narrativas que constituem sujeitos.

${ }^{21}$ LACLAU / MOUFFE, Hegemonia e estratégia socialista, p. 238.

${ }^{22}$ LACLAU / MOUFFE, Hegemonia e estratégia socialista, p. 279.

${ }^{23}$ Cf. especialmente LACLAU / MOUFFE, Hegemonia e estratégia socialista, p. 264-265.

${ }^{24}$ LACLAU / MOUFFE, Hegemonia e estratégia socialista, p. 280. 
É disso que trata Foucault quando relaciona hegemonia e aleturgia. Este termo é um neologismo para designar a dimensão discursiva na qual se constituem e se manifestam as distinções fundamentais para o sujeito, como verdade e falsidade, justo e injusto etc. "Poderíamos chamar 'aleturgia' o conjunto dos procedimentos possíveis, verbais ou não, pelos quais trazemos à luz o que é posto como verdadeiro por oposição ao falso, ao escondido, ao indizível, ao imprevisível, ao esquecido" 25 . Ou seja, a aleturgia refere-se à dimensão da "manifestação da verdade" que sustenta o "exercício de governo" vigente; ela remete à constituição da racionalidade que tem como correlato o governo. Segundo Foucault, não se pode pensar "nenhuma hegemonia que possa se exercer sem alguma coisa como uma aleturgia" "26. Assim, o sentido manifestado como aleturgia compõe em seu excesso o simbólico, a hegemonia. Ou seja, a hegemonia é forjada nas narrativas que organizam as manifestações cotidianas de verdade, na medida em que um sentido amplo extrapola as manifestações de sentido particulares da vida social.

A hegemonia tem fundamento, portanto, na narrativa que aos poucos extrapola o sentido particular do cotidiano. E só há possibilidade de contrapor diferentes narrativas umas às outras, de contrapor diferentes racionalidades umas às outras, no espaço aberto de poder que denominamos democracia.

Assim, a distinção entre os dois níveis de valor baseia-se, por um lado, na interpretação de Lefort segundo a qual democracia opõe-se a totalitarismo, por outro lado, na necessidade de precisar que a organização social socialista opõe-se à organização liberal. $\mathrm{Na}$ primeira oposição está em questão a indeterminação que garante o espaço da ação política, enquanto a segunda oposição diz respeito à ordem social fundada na coletividade ou na individualidade, dando centralidade à solidariedade ou à liberdade (a igualdade como "mesma liberdade", mesmas condições, etc. não subverte o paradigma liberal).

\section{IV - A realidade da disputa: imanência do inimigo na democracia liberal}

$\mathrm{Na}$ dimensão formal, democracia opõe-se a totalitarismo, que é determinação. Por outro lado, socialismo contrapõe-se a liberalismo na dimensão material, como modo de organização social concreta - socialismo não é oposto de "democracia", por isso pode-se falar em "democracia liberal" ou "democracia socialista".

Há hoje, na chamada "democracia liberal", ameaça real ao modo de existência de diversos grupos sociais. Não porque a democracia seja fictícia ou ilusória, mas porque o liberalismo organiza a maioria das relações concretas e, nessa medida, opõe-se muitas vezes

\footnotetext{
${ }^{25}$ FOUCAULT, Du gouvernement des vivants, p. 8.

${ }^{26}$ FOUCAULT, Du gouvernement des vivants, p. 8.
} 
às demandas por relações pautadas pela solidariedade ou pelo comum. Ora, mas o liberalismo não seria, justamente, o terreno do pluralismo?

"A pluralidade não é o fenômeno a ser explicado, mas o ponto de partida de análise" ${ }^{, 27}$. Acontece que ela só pode ser ponto de partida na forma democrática, jamais na forma totalitária. Nesta não há, justamente, pluralidade em jogo. Uma vez garantida a forma aberta da democracia, aí então a pluralidade passa a fazer parte das questões políticas. E por uma confusão entre os níveis da forma e da ordem social ela foi pensada como autonomia relativa, para o que a crítica de Laclau e Mouffe vem a calhar. Eles procuram mostrar como a "identidade precária" dos espaços ou registros sociais não respondem a uma "autonomia total", nem a uma "subordinação total"28. A crítica interessa porque ressalta a flutuação que articula diferentes registros sociais, no sentido de que "as práticas articulatórias têm lugar não apenas no interior de espaços sociais e políticos dados, mas entre eles" ${ }^{29}$. Significa que a pluralidade aberta pela indeterminação da forma democrática não significa necessariamente a autonomia relativa dos registros sociais, como supõe o liberalismo e, com ele, a crítica ao liberalismo que pretende recuperar certa unidade essencial ou normatividade imanente.

Vale o mesmo para a crítica que pretende apostar na autonomização como radicalização da democracia, pois aqui há a confusão entre democracia como indeterminação e democracia como imaginário igualitário. Este último foi o modo pelo qual o liberalismo confundiu-se com democracia. Ora, o que resta de "esquerda" em um projeto de "democracia radical" quando o pluralismo - a validade de cada identidade é um momento num sistema relacional e basta-se enquanto tal; nisso estamos de acordo e poderíamos denominar "nominalismo em história" - é democrático "na medida em que a autoconstitutividade de cada um de seus termos é o resultado dos deslocamentos do imaginário igualitário" 30 ? Significa que o imaginário democrático é liberal por excelência?

Se "o projeto de uma democracia radical e plural" de Laclau e Mouffe, "num sentido primário, nada mais é do que a luta por uma autonomização máxima de esferas, com base na generalização da lógica equivalencial igualitária”, então a democracia radical em questão é um aprofundamento do liberalismo. De fato, Laclau e Mouffe vinculam democracia e liberalismo, confundindo modos distintos de organização material ${ }^{31}$, ou melhor,

\footnotetext{
${ }^{27}$ LACLAU / MOUFFE, Hegemonia e estratégia socialista, p. 220.

${ }^{28}$ LACLAU / MOUFFE, Hegemonia e estratégia socialista, p. 220.

${ }^{29}$ LACLAU / MOUFFE, Hegemonia e estratégia socialista, p. 220.

${ }^{30}$ LACLAU / MOUFFE, Hegemonia e estratégia socialista, p. 252.

31 De modo análogo, Foucault concentra a análise do liberalismo na Alemanha do pós-guerra na concorrência, situando a organização material e discursiva no nível da forma do exercício de governo. Em $O$ nascimento da biopolitica Foucault discute a fundação de um Estado alemão no pós-guerra elidindo a questão da democracia. A concorrência, como ele mostra, é o sentido último da racionalidade liberal; porém, a concorrência não explica a forma do governo aberta na qual a racionalidade (neo)liberal pode tornar-se hegemônica.
} 
confundindo a forma aberta da democracia com um tipo específico de "gerenciamento da positividade social". Essa confusão aparece, por exemplo, na sequência de duas frases com caráter distinto uma da outra: "É a própria noção de cidadania que se transforma com o Estado de bem-estar social, na medida em que agora se atribuem 'direitos sociais' ao cidadão. Consequentemente, as categorias 'justiça', 'liberdade', 'equidade' e 'igualdade' têm se redefinido e o discurso liberal-democrático tem sido profundamente modificado por esta ampliação da esfera dos direitos"32. Ora, não se trata de uma "consequência", simplesmente porque não se trata de uma ampliação dos direitos liberais aos sociais, como se fosse uma passagem de grau e sem, justamente, antagonismos entre direitos liberais e direitos sociais.

Nesse sentido, se a crítica da desigualdade política desloca-se para uma crítica da desigualdade econômica ${ }^{33}$, trata-se de movimentos que a indeterminação permite entre liberalismo e socialismo, quando está em questão lutar por direitos e disposições que organizem materialmente a vida social. Mas isso não significa que a oposição entre a primazia dos direitos liberais e a primazia dos direitos sociais tenha sido reduzida a uma situação relativamente estável que abarque igualmente os dois lados; ao contrário, essa oposição é a base dos antagonismos que a democracia permite, o que não os torna sempre menos violentos ou decisivos. Por isso não podemos concordar com a fórmula que resume o projeto de Laclau e Mouffe. Para eles, "a tarefa da esquerda, pois, não pode ser renunciar à ideologia liberal-democrática, mas, ao contrário, aprofundá-la e expandi-la na direção de uma democracia radical e plural ${ }^{34}$. Ora, o aprofundamento concreto do liberalismo após os anos 1980 (quando eles publicam o livro em questão), e principalmente no século XXI, mostra que a democracia radical está longe e que o imaginário conservador ganha espaço. Quando o socialismo volta ao vocabulário, por exemplo com Bernie Sanders nos Estados Unidos, é para se contrapor - democraticamente - ao liberalismo.

Mouffe analisa a contradição denunciada por Schmitt entre democracia e liberalismo no artigo "Carl Schmitt and the paradox of liberal democracy". Porém, a adesão ao adjetivo "liberal" faz com que ela recuse a crítica de Schmitt a partir de um movimento contraditório, passando do vínculo entre "liberalismo" e "humanidade", essencial na crítica elaborada por Schmitt, ao vínculo entre "liberalismo" e "pluralismo". Ora, o pluralismo não é uma perspectiva exclusiva do liberalismo - e quando o liberalismo é pluralista ele é antipolítico, pois dissolve as relações entre o que há de plural, compartimentando as esferas da vida política. Parece ser preciso pensar um pluralismo socialista, em que as diversas esferas e condições sociais sejam pensadas em função de suas relações, e não como elementos justapostos por uma coexistência supostamente harmônica, garantida pelo

${ }^{32}$ LACLAU / MOUFFE, Hegemonia e estratégia socialista, p. 248. No mesmo sentido, cf. p. 258.

${ }^{33}$ LACLAU / MOUFFE, Hegemonia e estratégia socialista, p. 239.

${ }^{34}$ LACLAU / MOUFFE, Hegemonia e estratégia socialista, p. 264. 
conceito humanista de fundo, aquele que afirma a abstrata igualdade de todos enquanto homens de direito.

Quando, em Hobbes aquém do liberalismo, Lebrun discute o liberalismo como o momento de instituição de um limite ao poder soberano, recusando com isso a tese de Leo Strauss a respeito da paternidade hobbesiana do liberalismo, ele entende que os direitos liberais são efetivamente este limite. Porém, como nota Schmitt, os liberais não têm instrumentos para os casos limite, para as crises, para os momentos em que certa normalidade balança. Afinal, não há direito liberal que limite efetivamente a soberania do sujeito de decisão; não há exercício de direitos subjetivos que se contraponha às decisões sobre medidas de exceção e, muito menos ainda, à suspensão do direito positivo. O direito humano abstrato não interfere na suspensão do direito de fato, nem como um todo, nem nas "pequenas" suspensões diárias (medidas de exceção). Vale notar a diferença entre as medidas de exceção em certa normalidade democrática específica (liberal, por exemplo), e o estado de exceção como tal, que é já a fronteira que afoga qualquer normalidade democrática.

Mas por que se imagina, com Lebrun, que os direitos liberais limitam o poder soberano? Provavelmente porque há uma supervalorização do sistema jurídico e da representação política, sem que se considere a abstração desses elementos quando tratados como lugar neutro em relação às posições políticas. A supervalorização do sistema jurídico, que hoje ganha concretamente a prerrogativa da decisão, não seria o efeito da premissa de Carl Schmitt, segundo a qual a decisão é um elemento especificamente jurídico?

É verdade que Schmitt dirige forte crítica a Krabbe e Kelsen, na medida em que a tese central destes "se apoia na tese de que apenas o direito é soberano, não o Estado" 35 . Trata-se para Schmitt de criticar a "identidade do Estado e da ordem jurídica"36. Este tipo específico de formalismo não pode responder à pergunta por quem decide, nem no caso extremo, nem nas transformações internas ao próprio direito positivo. "Em toda transformação há uma auctoritatis interpositio [mediação da autoridade]. Da simples qualidade jurídica de um preceito não se pode deduzir que pessoa individual ou que entidade concreta pode reivindicar para si tal autoridade" ${ }^{37}$. Ora, diante desse "quem", a nossa época parece recolocar anacronicamente no modelo schmittiano (apesar de Schmitt) a identidade hobbesiana entre decisão (pessoa, quem decide) e sistema jurídico, já que na "vida efetiva" de nosso século - este que herda a abstração do direito liberal, sem contraposto desde os aos 1980 - é o sistema jurídico, com suas Cortes nacionais e internacionais, que assume essa função.

\footnotetext{
${ }^{35}$ SCHMIT'T, Teología politica, p. 25.

${ }^{36}$ SCHMITT, Teología politica, p. 25.

${ }^{37}$ SCHMITT, Teología politica, p. 32.
} 
Assim, a história concreta parece colocar em cena a identidade que Schmitt dissolvia teoricamente: no liberalismo o sistema judiciário é transformado paulatinamente em sujeito da soberania. Este parece ser o efeito da necessidade de encontrar no modelo abstrato dos direitos liberais um ponto último de decisão efetiva. É uma personificação disfarçada, já que a posição política do sujeito de decisão fica obscurecida pelo ideal abstrato do direito universal. O "quem" decide é forjado na narrativa hegemônica, no ethos liberal, na racionalidade de governo que domina a determinação do modo de ser do sujeito do século XXI.

Com isso, a confusão entre democracia e liberalismo, na figura do "Estado democrático de direito", reedita o vínculo moderno entre soberania e decisão como conceito jurídico, vinculando poder político e direito, de modo que "a faculdade de derrogar as leis vigentes, seja com caráter geral ou especial, é o atributo mais genuíno da soberania",38. Mas e se a decisão não for elemento jurídico, porém político, então essa prerrogativa não é do sistema judiciário. O liberalismo, recusando o problema extremo, aceitando e naturalizando as medidas de exceção cotidianas e apostando as fichas cada vez mais em um normativismo precário - e perigoso, já que é responsável direto pela força política do sistema jurídico, cujas posições políticas e morais se escondem na suposta frieza dos procedimentos - é saída anticoletiva e, nessa medida, antissocial.

A tarefa crítica e política no século XXI parece ser, principalmente, mostrar que há espaço para nova racionalidade no espaço aberto e indeterminado do poder. Com a democracia, que é condição de possibilidade de luta por uma racionalidade hegemônica distinta da liberal, pode-se lutar por um modelo socialista de organização material, por um modo solidário de ser.

Portanto, o campo de disputa está aberto quando há democracia. Isso é condição para a luta por uma forma de vida socialista. Para compreender a dimensão dessa abertura é fundamental o diagnóstico crítico segundo o qual o liberalismo é uma racionalidade contingente e, portanto, ultrapassável. "Consenso na sociedade liberal-democrática é - e será sempre - a expressão de uma hegemonia e a cristalização de relações de poder" ${ }^{\text {"39 }}$.

\section{V - O sentido da disputa: por uma democracia socialista}

Socialismo não é o contrário de democracia porque é modo material de organização social (moral antes de ser econômico). Socialismo é contrário a (neo)liberalismo e a disputa por hegemonia é interna à forma aberta da democracia, depende dela. Afinal, não há práticas articulatórias em luta sem indeterminação prévia, sem democracia.

\footnotetext{
38 SCHMITT, Teología política, p. 15.

${ }^{39}$ MOUFFE, "Schmitt and the paradox of liberal democracy", p. 49.
} 
Por isso não é indiferente se a resistência se formula em lutas coletivas ou individualmente, ao contrário do que asseguram Laclau e Mouffe quando mencionam "formas de resistência" que "se manifestam não na forma de lutas coletivas, mas através de uma afirmação do individualismo" coletiva é índice do limite político de Foucault. Laclau e Mouffe acusam a esquerda de perder a possibilidade de articular discursivamente as lutas individualistas. Isso não significa deixar o campo da esquerda? Eles ironizam: "a esquerda, naturalmente, está despreparada para assumir estas lutas, as quais ela ainda hoje descarta como 'liberais'. Daí o perigo de que elas possam ser articuladas por um discurso de direita, de defesa de privilégios" ${ }^{\text {" }}$. Na acusação de Laclau e Mouffe parece que a luta sofre de um vazio quanto a seu sentido político-discursivo e que seria, portanto, neutra, pronta para ser articulada a posteriori por um discurso de direita ou de esquerda... Não se pode aceitar a ideia de que "a forma do antagonismo como tal é idêntica em todos os casos" $"$, pois isso esvaziaria o antagonismo de seu sentido político. Apenas este ou aquele "momento identitário", esta ou aquela luta de resistência pode ser efetivamente de resistência, isto é, pode ser entendida como minoritária e, portanto, como inimigo imanente à democracia liberal. Afinal, democracia é forma, mas não é vazia de múltiplas determinações empíricas (pluralidade) e, com isso, de discursos hegemônicos já formulados.

A dificuldade de fundo é a decisão pelo valor político deste ou daquele movimento, pelo horizonte político que cada um tem em vista, pela "representação de um bem" (mundus vult decipi). Falta em Laclau e Mouffe o horizonte da prática articulatória - falta o sentido da ação política em termos de ação com finalidade. Falta explicitar o valor que define a direção das práticas hegemônicas. Como Laclau e Mouffe notam, nem todo movimento social é progressista, "novas lutas não têm necessariamente um caráter progressista" 43 ... logo, nem toda luta por hegemonia é progressista; nem toda luta pode ser articulada como discurso de esquerda, como narrativa socialista. Em tempo: falamos "socialismo" deslocando-o de seu sentido clássico, vinculado à socialização dos meios de produção; o termo precisa ter sentido renovado no mesmo nível de seu avesso, o liberalismo. É preciso transformar discursivamente o socialismo em ethos, encarnando-o na mesma dimensão que o liberalismo atingiu, particularmente depois dos anos 1980.

O horizonte de uma democracia socialista não é o não-direito, não é anarquia; o horizonte político de uma democracia socialista é um espaço aberto de disputa política com a posição política dos sujeitos de decisão sempre explicitadas e expostas ao debate e à crítica pública - em que o modo de ser solidário se sobreponha ao ethos liberal. Ora, se "a

\footnotetext{
${ }^{40}$ LACLAU / MOUFFE, Hegemonia e estratégia socialista, p. 249.

${ }^{41}$ LACLAU / MOUFFE, Hegemonia e estratégia socialista, p. 249.

${ }^{42}$ LACLAU / MOUFFE, Hegemonia e estratégia socialista, p. 250.

${ }^{43}$ LACLAU / MOUFFE, Hegemonia e estratégia socialista, p. 254.
} 
união do poder supremo fático e jurídico é o problema capital do conceito de soberania"44, então pensemos em um poder fático socialista vinculado a um sistema jurídico dessacralizado. Significa disputar a hegemonia em um sistema inevitavelmente conflituoso. A perspectiva coletiva não é universal, nem se pode suspeitar que ela se sobreporá pela razão a interesses individuais, reafirmados no modo individualista e concorrencial de ser.

Portanto, não se pode deixar de reconhecer que o antagonismo opera efetivamente na ordem social e que seus fundamentos são sempre morais, contingentes e circunstanciais; em um espaço político aberto, democrático, os fundamentos dos antagonismos estão sempre em disputa. A aleturgia é igualmente dimensão em disputa, da qual emerge certa hegemonia como racionalidade vigente.

\section{Referências Bibliográficas}

FOUCAULT, M. Naissance de la biopolitique (1978-1979). Paris: Hautes Études/Gallimard/Seuil, 2004

FOUCAULT, M. Du gouvernement des vivants (1979-1980). Paris: EHESS/Gallimard/Seuil, 2012

MOUFFE, C. "Schmitt and the paradox of liberal democracy", In: The democratic paradox. London/New York: Verso, 2005

LACLAU, E. / MOUFFE, C. Hegemonia e estratégia socialista: por uma politica democrática radical. trad. Joanildo A. Burity, Josias de Paula Jr. e Aécio Amaral. Brasília: Intermeios, 2015

LEFORT, C. "A questão da democracia”. In: Pensando o politico: ensaios sobre democracia, revolução e liberdade, tradução Eliana M. Souza. Rio de Janeiro: Paz e Terra, 1991

RANCIÈRE, J. O desentendimento. tradução de Ângela Leite Lopes. São Paulo: Ed. 34.

SCHMITT, C. Teologia politica. traducciones de Francisco Javier Conde y Jorge Navarro Pérez, epílogo de José Luis Villacañas. Madrid: Editorial Trotta, 2009

VIVEIROS DE CASTRO, E. Metafísicas Canibais: elementos para uma antropologia pós-estrutural. São Paulo: Cosac Naify, 2015.

${ }^{44}$ SCHMITT, Teologia politica, p. 22. 